\title{
BEBÊS FILHOS DE USUÁRIAS DE DROGAS: CONTRIBUIÇõES PARA O CUIDADO DE ENFERMAGEM PEDIÁTRICA EM COMUNIDADES ACOLHEDORAS
}

\section{Pôster}

Autores deste trabalho:

Ana Caroline Melo dos Santos: Faculdade Regional da Bahia (UNIRB)

Renise Bastos Farias Dias: Universidade Federal de Alagoas

Bárbara Fernanda Santos Alcantara: Universidade Federal de Alagoas

Thaynara Silva dos Santos Oliveira: Universidade Federal de Alagoas

Lino José da Silva: Universidade Federal de Alagoas

Ana Beatriz Amorim Sales : Universidade Federal de Alagoas

Bruna Brandão dos Santos: Universidade Federal de Alagoas

Elaine Virgínia Martins de Souza Figueiredo : Universidade Federal de Alagoas

Área do Trabalho: Enfermagem pediátrica

Data da submissão: 10/08/2018 às 10:53

\section{Justificativa}

A saúde dos bebês filhos de mulheres usuárias de drogas assistidas em Comunidades acolhedoras é uma preocupação real e atual. A enfermagem possui um papel imprescindível na atenção integral à saúde destes bebês que, quando expostos a drogas no período pré-natal, podem apresentar uma condição denominada Síndrome de Abstinência Neonatal (SAN), que podem gerar consequências danosas à sua saúde.

Desta forma, torna-se relevante discutir sobre o contexto de acolhimento e cuidado destes bebês em Comunidades acolhedoras, a fim de ressaltar a importância da atuação do enfermeiro nestes serviços.

\section{Objetivo(s)}

Discutir sobre a importância do cuidado de enfermagem ao bebê, filho de mãe toxicodependente assistida em Comunidades acolhedoras.

\section{Método(s)}

Trata-se de um estudo qualitativo, recorte de uma pesquisa de doutorado aprovada pelo CEP/UFAL sob o no $2.408 .885 / 2018$, desenvolvida em comunidades acolhedoras de um município do agreste alagoano, onde foram entrevistadas 29 mulheres em idade fértil, sendo três acompanhadas de seus bebês menores de 6 meses.

\section{Resultado(s)}

Observou-se a ausência do enfermeiro nas Comunidades acolhedoras; identificou-se o quanto as Comunidades estão desprovidas de um acolhimento diferencial às mães acompanhadas de seus filhos e a necessidade de capacitação dos profissionais que ali trabalham, com foco na prestação de assistência diferenciada, qualificada e humanizada ao binômio mãe-filho. A presença do enfermeiro nas Comunidades foi identificada como fator indispensável para a atenção integral à saúde infantil, 


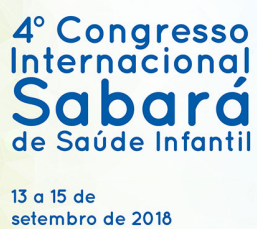

$4^{\circ}$ Congresso Internacional

de Saúde Infanti

setembro de 2018
Hotel Maksoud Plaza
Alameda Campinas, 150
Säo Paulo- Brosil

incluindo no seu processo de cuidados: a assistência ao binômio mãe-filho; o acompanhamento do crescimento e desenvolvimento destes bebês, com ênfase na avaliação de sinais e sintomas da SAN e no manejo qualificado destes casos; além do acompanhamento neurocognitivo do bebê; orientações sobre a indicação e contraindicação da amamentação; e promoção da saúde, incluindo o cuidado ao bebê e a abordagem sobre os efeitos da toxicodependência na mãe, no bebê e na família.

\section{Conclusão (ões)}

Pode-se inferir sobre a importância da presença do enfermeiro nas Comunidades acolhedoras, trazendo olhar empático e crítico para preservação e proteção da vida da criança com adequada compreensão e reconhecimento de suas necessidades biopsicossociais e espirituais, buscando cuidado qualificado e adequado, minimizando as consequências neurocognitivas das drogas nos bebês e fortalecendo o vínculo mãe/família-filho. 